\title{
THERMODYNAMIC ANALYSIS AND PARAMETRIC STUDY OF PARALLEL FEED MED-TVC DESALINATION SYSTEM
}

\author{
A. O .Abd El-Monaem, A. R. Alghalban, F. Mahfouz and E. H. Farag \\ Mechanical Power Engineering Department, Faculty of Engineering \\ Menoufiya University, Shebin El-Kom, Egypt
}

\begin{abstract}
Multi Effect Desalination with Thermal Vapor Compression (MED-TVC) is one of the most effective desalination methods. It plays a vital role in the production of fresh water in many regions of the world especially in the Arabian countries. Parallel feed MED-TVC system has been modeled mathematically based on the first and second laws of Thermodynamics. A computer program has been developed using MATLAB program to simulate the system. A comparison between the program results and the data of actual plants has been conducted to verify the program's validity. The deviation between Model results and actual data has been found to be very small. The main design parameters that greatly influence the performance of MED-TVC plant have been identified. A parametric study has been carried out to investigate the effect of these parameters on the gain Ratio (GR), specific heat transfer area (SHTA) and specific total exergy destruction (STED). The obtained results indicated that the GR increases with increasing each of number of effects (NE), last effect temperature, salt concentration up to 2, and motive steam pressure. The SHTA increases with decreasing the top brine temperature (TBT) and/or motive steam pressure, while the SHTA decreases with increasing each of NE, the last effect temperature, and the salt concentration ratio. Moreover, the study has shown that STED increases with decreasing NE and/or TBT and increasing the motive steam pressure. The total and subsystems exergy losses of MED-TVC desalination system have been evaluated. The results show that the higher percentage of exergy destruction occurs in the ejector, which represents about $60 \%$ of the total exergy destruction. Meanwhile, the exergy destruction inside effects itself represents about $33 \%$ of the total exergy destruction in MED-TVC system.

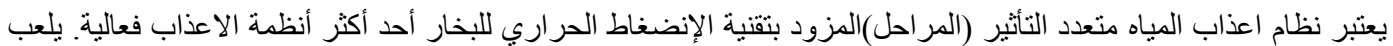

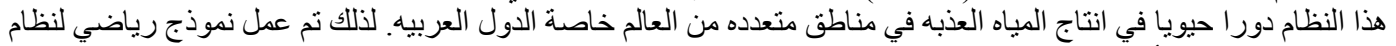

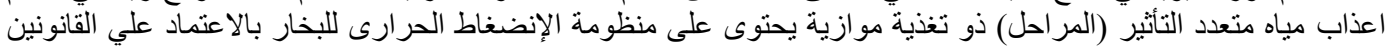

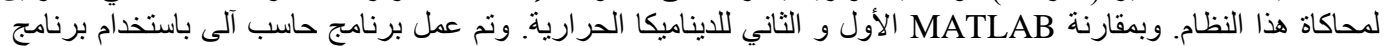

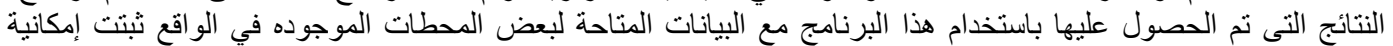

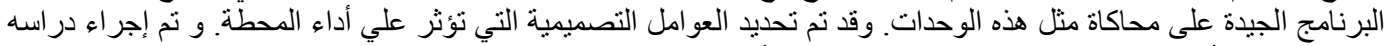

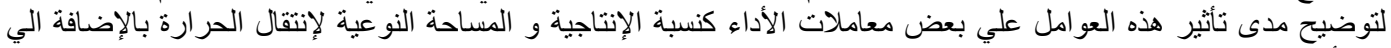

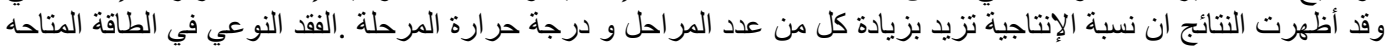

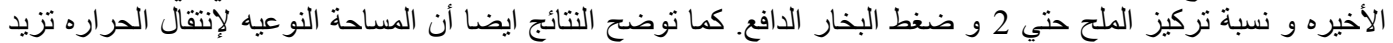

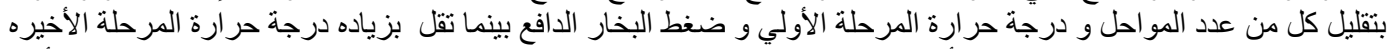

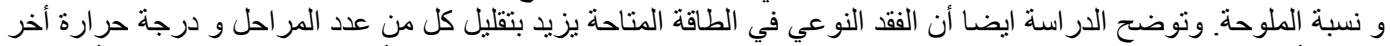

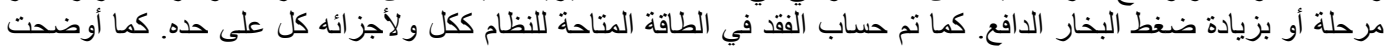
النتائج ان النسبة الأكبر للفقد في الطاقة المتاحة يكون في القاذف ويكون في حدود 60\% ويليه الفقد في المر احل ويكون في حدود \%33 من الفقد الكلي.
\end{abstract}

Keywords : MED-TVC, mathematical modeling, exergy analysis, parametric study. 


\section{INTRODUCTION}

Water is one of the most important substances on earth. Nearly three quarters of the earth's surface are covered with water. However, $97.5 \%$ of this amount is represented by the oceans. A major portion of the remaining $2.5 \%$ is frozen in glaciers, permanent snow cover, ice and permafrost. Less than $0.007 \%$ of the world's water is thus readily accessible for direct human use, and even that is very unevenly distributed. These limited freshwater resources in rivers and lakes are rapidly dwindling because of over-exploitation, consequent water quality degradation, increasing population and standards of living, and rapid industrialization and urbanization [1].The race for the second generation of the seawater desalination systems has been settled with Reverse Osmosis (RO) and low temperature MED. Both systems are characterized by their low energy consumption as compared to the Multi Stage Flash (MSF) system [2].

Conventional MED desalting system uses about half of the MSF pumping energy, and almost the same amount of thermal energy used by the MSF, if both have the same gain ratio [3]. However, a recent trend of using low-temperature MED allows the use of low temperature steam (lower than $70{ }^{\circ} \mathrm{C}$ ) as heat source, and consequently low equivalent work. This can bring the consumed mechanical energy of MED to be close to that consumed by the efficient RO system. Horizontal tubes falling-film evaporation with thermal vapor compression is the most dominating process in today's MED systems as adding the ejector to the MED system increases drastically the GR[4,5] . Low scale formation, easy operation, high GR, and operating with any available source of heat energy (e.g. waste heat from power plants), have caused the MED- TVC system to be used widely in Middle East countries [6]. GR is defined as the ratio of produced distillate mass flow rate to mass flow rate of external heat source steam.

Several studies have been reported on MED desalination system. Different mathematical models have been developed and most of these publications are based on the first law of thermodynamics [7-21]. A few researches are concerned with exergy analysis and calculation of exergy destruction [22-24].

El-Dessouky and Assassa [7] developed a mathematical model for each of MED and MEDTVC system. It was concluded that the GR of the MED-TVC system is much greater than that for the MED system.

Darwish et al. [8] performed a thermal analysis of MED-TVC system and compared between the MEDTVC system and MSF desalting system. They concluded that the conventional MED system can produce desalted water at a lower cost than the MSF system when both systems are supplied with steam extracted from a turbine of a power plant. The results also indicated that mechanical or thermal vapor compression desalting systems are more costeffective when compared with directly boileroperated MSF systems.

Ettouney et al. [10] developed a computer package for the design and simulation of thermal desalination processes including single effect desalination (standalone and vapor compression), Multi Stage Flash (brine circulation, brine mixing, once through and thermal vapor compression), and Multi Effect Desalination (parallel and forward feed, stand-alone and vapor compression).

El-Dessouky et al. [11] studied the effect of the heating steam temperature, salinity of the intake seawater, and $\mathrm{NE}$ on performance parameters including GR, SHTA, specific cooling water flow rate, and conversion ratio for parallel and parallel/cross feed MED. It has been concluded that the parallel/cross feed MED system has a better performance than parallel feed MED system and the forward feed MED system has better performance compared with parallel feed MED and MSF systems.

Jernqvist et al. [12] developed a general computer program to simulate, rate and optimize all types of thermal desalination processes. Ashour [13] showed that the GR increases by increasing the TBT due to decreasing the required sensible heat to warm-up the feed water to saturation temperature.

Aybar[14] presented the results of using waste heat from the North Cyprus steam power plant to produce make-up water for the boilers using a simple MED system. The results showed that the simple MED system can supply $83 \%$ of the water required by the power plant and the system productivity increases with decreasing temperature difference between hot and cold sides of the effects.

Ettouney [15] developed a visual basic computer package for the design and analysis of thermal and membrane desalination processes including reverse osmosis, single-effect MED with/without thermal or mechanical vapor compression, and MSF systems.

Nafey et al. [16] developed a visual design and simulation package using Visual Basic to simulate different types and configurations of desalination processes including MSF, MED, MED-TVC, MED$\mathrm{MVC}$, and RO.

Ameri et al. [17] presented a conceptual design for a four-effect MED-TVC system that uses waste heat 
from gas turbine power plant to produce potable water. The results showed that the TBT has a minor effect on GR, while the SHTA significantly decreases with increasing TBT.

Jiangang $\mathrm{Ji}$ et al. [18] developed a mathematical model for a single-effect TVC desalination system. The effects of the operating conditions on the system performance were studied. The results showed that the GR increases with increasing the cooling water flow rate to values higher than design value. The GR reaches a peak point when the cooling water flow rate increases to a definite level.

Kamali et al. [19] developed a mathematical model which predicts the influence of different parameters on heat transfer coefficient, temperature and pressure, total capacity and GR of the MED-TVC. It was concluded that temperature and pressure inside the system directly depend on temperature and pressure inside the condenser. It was also concluded that increasing in condenser heat transfer surface area decreases TBT and increases GR.

Ameri et al. [20] studied the effects of different design parameters, including number of effects, temperature difference across effects, feed water temperature, and boiler pressure on the specifications of a MED-TVC system including GR, SHTA and cooling sea water mass flow rate. It was concluded that increasing boiler pressure increases both GR, SHTA and decreases the cooling seawater mass flow rate.

Bin Amer [21] developed a steady state mathematical model of the ME-TVC desalination system. The model was solved using Engineering Equations Solver (EES) to evaluate the system performance. Mathematical modeling optimization was studied for different NE using two different MATLAB algorithms; Smart Exhaustive Search Method and Sequential Quadratic Programming. The Results showed that the maximum GR varied between 8.5 and 18.5 for 4 and 12 effects with the optimal top brine temperature ranging between 55.8 and $67.5^{\circ} \mathrm{C}$. The optimal ranges of compression and entrainment ratios are between 1.81 to 3.68 and 0.73 to 1.65 respectively.

Al-Mutaz et al. [22] developed a steady-state mathematical model of MED-TVC system. The model equations are solved using a developed MATLAB code. The influence of important design and operating variables such as NE, motive steam pressure, TBT, temperature difference across effects, and feed water temperature on the performance of the plant was investigated.

Hamed et al. [23] compared between the exergy destroyed from conventional MED system, mechanical vapor compression (MVC) system and TVC system. It was concluded that TVC system has the lowest exergy destruction. The study also showed that The main sources of the exergy destruction in the
TVC system are the first effect and ejector. It was also concluded that overall exergy losses can be significantly reduced by increasing $\mathrm{NE}$ and the ejector entrainment ratio, and by decreasing the TBT. Chennan Li [24] proposed a combined power and desalination system driven by low grade heat sources such as solar energy, geothermal or waste heat. This system combines a Supercritical Organic Rankine Cycle (SORC), an ejector and a Multi Effect Desalination system. A parametric study and exergy analysis were developed. The combined system has overall exergy efficiency close to $40 \%$ for salt concentration of $35 \mathrm{~g} / \mathrm{kg}$ using a low temperature heat source at $150^{\circ} \mathrm{C}$.

It can be concluded from the above literature review that there is a need to perform a comprehensive parametric study on the performance of the MEDTVC system basing on the first and second laws of thermodynamics.

The present paper presents a mathematical model for parallel feed Multi Effect Desalination Thermal Vapor Compression system (MED-TVCPF) with feed heaters and flashing boxes. The mathematical model is based on mass, energy, and exergy balances. Moreover, a parametric study has been conducted to investigate the effect of different design and operation parameters on the performance parameters such as Gain Ratio (GR), Specific Heat Transfer Area (SHTA) and Specific Total Exergy Destruction (STED) of the system.

\section{PROCESS DISCRIPTION}

Figure (1) shows the layout of MED-TVC-PF system. The system consists of $\left(N_{E}\right)$ falling film evaporators (effects), $\left(N_{E^{-}}-1\right)$ feed heaters, $\left(N_{E}\right)$ flashing boxes, steam jet ejector, and a condenser. The seawater at mass flow rate $\left(M_{S W}\right)$ and temperature $\left(T_{S W}\right)$ enters the condenser. Therefore, the temperature of seawater increases to $\left(T_{F_{n}}\right)$ while a part of the generated vapor in the last effect $\left(D_{F}\right)$ is condensed. The condensation of $\left(D_{F}\right)$ requires more water than that is needed to feed all effects $\left(F_{t}\right)$. The additional amount of water is termed as cooling water $\left(M_{C W}\right)$ which is returned back to the sea. The feed water $\left(F_{t}\right)$ passes through successive feed heaters and is divided over effects into $F_{1}, F_{2}, \ldots, F_{n}$ at temperatures $T_{F_{1}}, T_{F_{2}}, \ldots ., T_{F_{n}}$. The motive steam $(S)$ enters the steam jet ejector as a saturated steam with a pressure $\left(P_{s}\right)$. This steam $(S)$ is taken from an external boiler or extracted from steam turbine of a steam power station. In the nozzle section of the ejector, the steam pressure is reduced to a vacuum pressure causing the entrained steam $\left(D_{r}\right)$ to be withdrawn to the ejector. The two streams $(S)$ and $\left(D_{r}\right)$ are mixed then the mixture pressure is raised to the discharged pressure $\left(P_{d}\right)$ in the diffuser section of ejector. 
In the first effect, the stream $\left(S+D_{r}\right)$ condenses and exists as a saturated liquid. The heat liberated during condensation heats up the feed water $\left(F_{l}\right)$ from $\left(T_{F l}\right)$ to $\left(T_{1}\right)$ at which boiling occurs and an amount of vapor is released. The generated vapor enters a wire mesh demister to remove the entrained brine droplets. The vapor $\left(D_{l}\right)$ is at a temperature $\left(T_{V_{l}}\right)$ which is lower than $\left(T_{l}\right)$ by Boiling Point Elevation $(B P E)$ because the boiling process occurs in salty water and the generated vapor is salt free. The condensate $\left(S+D_{r}\right)$ is divided to $(S)$ which is pumped back to the boiler or to the steam power station and $\left(D_{r}\right)$ which enters the $1^{\text {st }}$ flashing box where the pressure is reduced from $\left(P_{d}\right)$ to $\left(P_{V_{I}}\right)$ that corresponds to the saturation pressure at $\left(T_{V_{l}}\right)$. So, a flashing process takes place and an amount of vapor $\left(D_{F B}\right)$ is generated. This amount of vapor is added to $\left(D_{l}\right)$ before entering the first feed heater in which, the feed water $\left(F_{1}\right)$ is heated from $\left(T_{F_{2}}\right)$ to $\left(T_{F_{1}}\right)$ and a small part of the entering vapor condenses. So, the saturated vapor is converted to wet vapor which condenses in the second effect. The heat librated during condensation process is used as the heat source for the second effect. The brine rejected from the first effect $\left(B_{1}\right)$ enters the second effect to generate more vapor by flashing. This is because of decreasing the pressure of brine from $\left(P_{1}\right)$ which is the saturation pressure at $\left(T_{1}\right)$ to $\left(P_{2}\right)$.

These processes are repeated from the second effect to the $\mathrm{n}^{\text {th }}$ effect. The condensed water from each effect except that of the first one is collected in the desalinated water pipe. The total brine $\left(B_{n}\right)$ is rejected from the $\mathrm{n}^{\text {th }}$ effect at $\left(T_{n}\right)$.

\section{MODEL ASSUMPTIONS}

The following assumptions have been made during the model development process:

1. The system operation is in the steady state conditions.

2. The generated vapor in each effect is salt free.

3. The heat loss to surroundings is neglected.

4. Non-condensable gas is removed by the pretreatment and venting system.

5. The demister friction, pipe friction and the condensation pressure drop are negligible.

\section{Model equations}

Mass, material, energy and exergy balances are applied to each component in addition of calculating the rate of heat transfer as follows:

- Mass and Salt balance of the whole system.

$F_{t}=D_{t}+B_{n}$

$X_{F} \cdot F_{t}=X_{n} \cdot B_{n}$

By substitution from (1) into (2), the total feed water can be related to the total desalinated water as follows:

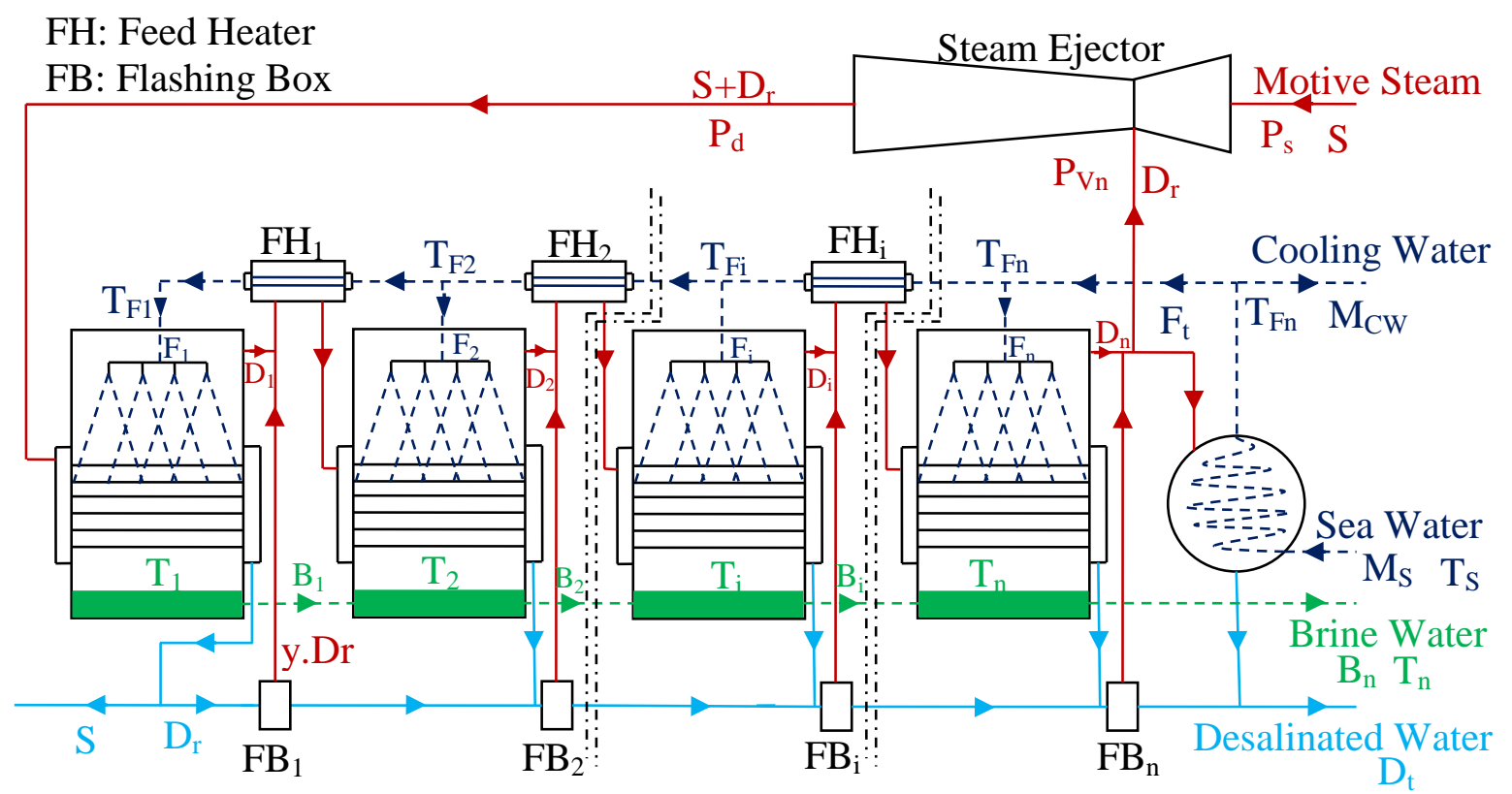

Figure (1) Parallel feed MED-TVC system with FH and FB 


$$
F_{t}=D_{t} \cdot \frac{X_{n}}{X_{n}-X_{F}}
$$

Where $X_{F}, X_{n}$ are the salt concentration of feed seawater and brine rejected from the $\mathrm{n}^{\text {th }}$ effect in $\mathrm{ppm}$ respectively.

\section{- Mass, Salt and Energy balance of $1^{\text {st }}$ effect}

$$
\begin{aligned}
& B_{1}=F_{1}-D_{1} \\
& X_{F} \cdot F_{1}=X_{1} \cdot B_{1} \\
& \left(S+D_{r}\right) \cdot L_{d}=D_{1} \cdot L_{V_{1}}+F_{1} \cdot C_{P} \cdot\left(T_{1}-T_{F_{1}}\right)
\end{aligned}
$$

Where $X_{1}$ is the salt concentration of the $1^{\text {st }}$ effects brine.

$L_{d}$ is the latent heat of condensation of the heating steam at the temperature of $T_{d}$.

$L_{V l}$ is the latent heat of evaporation at a temperature of $T_{V_{l}}$ which is lower than $T_{l}$ by an amount of $B P E$.

Both $B P E$ and $C_{P}$ are functions of boiling temperature and brine salt concentration. Values of $B P E$ and $C_{P}$ can be obtained from [22].

\section{- Rate of heat transfer of $1^{\text {st }}$ effect}

$$
Q_{E_{1}}=\left(S+D_{r}\right) \cdot L_{d}=U_{E_{1}} \cdot A_{1} \cdot\left(T_{d}-T_{1}\right)
$$

where $U_{E_{l}}$ is the overall heat transfer coefficient of the $1^{\text {st }}$ effect.

\section{- Exergy balance of $1^{\text {st }}$ effect}

The exergy destruction of any system component can be obtained by applying the exergy balance which is generally expressed as:

$$
\sum\left(1-\frac{T_{o}}{T_{k}}\right) Q_{k}^{\cdot}-W^{\bullet}+\sum_{\text {in }} m^{\bullet} \psi-\sum_{\text {out }} m^{\bullet} \psi-X_{\text {dest }}^{\cdot}=0
$$

where $\psi$ is the specific exergy of inlet or exit stream.

Deducing the above equation releases the exergy destruction of $1^{\text {st }}$ effect in the following form:

$$
\begin{aligned}
X_{E_{1}}^{\bullet} & =Q_{E_{1}} \cdot\left(1-\frac{T_{o}}{T_{d}}\right)-D_{1} \cdot L_{V_{1}}\left(1-\frac{T_{o}}{T_{V_{1}}}\right) \\
& +F_{1} \cdot C_{P} \cdot\left(\left(T_{F_{1}}-T_{1}\right)-C_{P} \cdot \ln \left(\frac{T_{F_{1}}}{T_{1}}\right)\right)
\end{aligned}
$$

The first term represents the exergy of the heat input to the $1^{\text {st }}$ effect. The second term represents the exergy of heat of evaporation on the effect tubes while the third term can be deduced from the difference in exergy between the inlet and outlet steams.

\section{- Energy balance of $1^{\text {st }}$ flashing box}

In the $1^{\text {st }}$ flashing box, the pressure of the saturated liquid $D_{r}$ is reduced from $P_{d}$ to $P_{V_{I}}$. So, the saturated liquid converts due to flashing to wet vapor with a dryness fraction of $(y)$. So, the $1^{\text {st }}$ flashing box's energy balance can be expressed as:

$$
D_{r} \cdot C_{P} \cdot\left(T_{d}-T_{V_{1}}\right)=y \cdot D_{r} \cdot L_{V_{1}}=D_{F B_{1}} \cdot L_{V_{1}}(10)
$$

\section{- Exergy balance of $1^{\text {st }}$ flashing box}

Applying exergy balance on the $1^{\text {st }}$ flashing box, the following equation can be obtained:

$$
\begin{aligned}
X_{F B_{1}}^{\bullet} & =D_{r} C_{P}\left(T_{d}-T_{V_{1}}-T_{O} \ln \left(T_{d} / T_{V_{1}}\right)\right) \\
& -D_{F B_{1}}\left(L_{V_{1}}-T_{O}\left(s_{V_{1}}-s_{L_{1}}\right)\right)
\end{aligned}
$$

\section{- Energy balance of $1^{\text {st }}$ feed heater}

The energy generated during the partially condensation of saturated steam is equal to the energy gained by the feed water of the first effect $\left(F_{l}\right)$. So,

$$
F_{1} \cdot C_{P} \cdot\left(T_{F_{1}}-T_{F_{2}}\right)=\left(D_{1}+D_{F B_{1}}\right) \cdot Z \cdot L_{V_{1}}
$$

where $Z$ is the amount of condensed vapor.

\section{- Mass, Salt and Energy balance of $2^{\text {nd }}$ effect}

$$
\begin{aligned}
& B_{2}=F_{1}+F_{2}-D_{1}-D_{2} \\
& X_{F} \cdot F_{1}+X_{1} \cdot B_{1}=X_{2} \cdot B_{2} \\
& \left(D_{1}+D_{F B_{1}}\right)(1-Z) L_{V_{1}}+B_{1} C_{P}\left(T_{1}-T_{2}\right) \\
& \quad=D_{2} L_{V_{2}}+F_{2} C_{P}\left(T_{2}-T_{F_{2}}\right)
\end{aligned}
$$

By substitution from equations (4), (9) and (11), the energy balance equation is expressed as:

$$
\begin{gathered}
D_{r} C_{P}\left(T_{d}-T_{V_{1}}\right)+D_{1}\left(L_{V_{1}}-C_{P}\left(T_{1}-T_{2}\right)\right) \\
-D_{2} L_{V_{2}}=F_{1}\left(C_{P}\left(T_{F_{1}}-T_{F_{2}}\right)-C_{P}\left(T_{1}-T_{2}\right)\right) \\
+F_{2} C_{P}\left(T_{2}-T_{F_{2}}\right)
\end{gathered}
$$


A. O .Abd El-Monaem, A. R. Alghalban, F. Mahfouz and E. H. Farag "THERMODYNAMIC.."

- Rate of heat transfer of $2^{\text {nd }}$ effect

$$
\begin{aligned}
Q_{E_{2}} & =D_{r} C_{P}\left(T_{d}-T_{1}\right)+D_{1} L_{V_{1}}-F_{1} C_{P}\left(T_{F_{1}}-T_{F_{2}}\right) \\
& =U_{E_{2}} \cdot A_{2} \cdot\left(T_{V_{1}}-T_{2}\right)
\end{aligned}
$$

- Exergy balance of $2^{\text {nd }}$ effect

$$
\begin{aligned}
X_{E_{2}}^{\cdot} & =Q_{E_{2}}\left(1-\frac{T_{o}}{T_{V_{1}}}\right) \\
& +F_{2} C_{p}\left(\left(T_{F_{2}}-T_{2}\right)-T_{o} \ln \left(\frac{T_{F_{2}}}{T_{2}}\right)\right) \\
& +B_{1} C_{p}\left(\left(T_{1}-T_{2}\right)-T_{o} \ln \left(\frac{T_{1}}{T_{2}}\right)\right) \\
& -D_{2} L_{V_{2}}\left(1-\frac{T_{o}}{T_{V_{2}}}\right)
\end{aligned}
$$

- Mass, salt and energy balances of $i^{\text {th }}$ effect

$$
\begin{aligned}
& B_{i}=\sum_{j=1}^{i}\left(F_{j}-D_{j}\right) \\
& X_{F} \cdot F_{i}+X_{i-1} \cdot B_{i-1}=X_{i} \cdot B_{i} \\
& D_{r} C_{P}\left(T_{V_{i-2}}-T_{V_{i-1}}\right) \\
& +\sum_{j=1}^{i-2} D_{j} C_{P}\left(\left(T_{V_{i-2}}-T_{V_{i-1}}\right)-\left(T_{i-1}-T_{i}\right)\right) \\
& +D_{i-1}\left(L_{V_{i-1}}-C_{P}\left(T_{i-1}-T_{i}\right)\right)-D_{i} L_{V_{i}}= \\
& \quad\left(\sum_{j=1}^{i-1} F_{j}\right) C_{P}\left(\left(T_{F_{i-1}}-T_{F_{i}}\right)-\left(T_{i-1}-T_{i}\right)\right) \\
& \quad+F_{i} C_{P}\left(T_{i}-T_{F_{i}}\right)
\end{aligned}
$$

- Rate of heat transfer of $i^{\text {th }}$ effect

$$
\begin{aligned}
Q_{E_{i}} & =\left(D_{r}+\sum_{j=1}^{i-2} D_{j}\right) C_{P} \cdot \Delta T_{E}+D_{i-1} \cdot L_{V_{i-1}} \\
& -\left(\sum_{j=1}^{i-1} F_{j}\right) C_{P} \cdot \Delta T_{F}=U_{E_{i}} \cdot A_{i} \cdot\left(T_{V_{i-1}}-T_{i}\right)
\end{aligned}
$$

- Exergy destruction of the $i^{\text {th }}$ effect

$$
\begin{aligned}
X_{E_{i}}^{\cdot} & =Q_{E_{i}}\left(1-\frac{T_{o}}{T_{V_{i-1}}}\right) \\
& +F_{i} C_{p}\left(\left(T_{F_{i}}-T_{i}\right)-T_{o} \ln \left(\frac{T_{F_{i}}}{T_{i}}\right)\right) \\
& +B_{i-1} C_{p}\left(\left(T_{i-1}-T_{i}\right)-T_{o} \ln \left(\frac{T_{i-1}}{T_{i}}\right)\right) \\
& -D_{i} L_{V_{i}}\left(1-\frac{T_{o}}{T_{V_{i}}}\right)
\end{aligned}
$$

- Energy balance of $i^{\text {th }}$ flashing box

$$
\begin{aligned}
\left(D_{r}+\sum_{j=1}^{i-1} D_{j}\right) \cdot C_{P} \cdot\left(T_{V_{i-1}}-T_{V_{i}}\right)= & \\
& \left(D_{r}+\sum_{j=1}^{i-1} D_{j}\right) \cdot y \cdot L_{V_{i}}
\end{aligned}
$$

- Exergy balance of $i^{\text {th }}$ flashing box

$$
\begin{aligned}
X_{F B_{i}}^{\cdot}= & \left(D_{r}+\sum_{j=1}^{i-1} D_{j}\right) C_{P}\left(\Delta T_{E}-T_{O} \ln \left(\frac{T_{V_{i-1}}}{T_{V_{i}}}\right)\right) \\
& -D_{F B_{i}} L_{V_{i}}\left(1-\left(T_{O} / T_{V_{i}}\right)\right)
\end{aligned}
$$

- Energy balance of $i^{\text {th }}$ feed heater

$$
\begin{aligned}
D_{F H_{i}} \cdot L_{V_{i}} & =\left(D_{i}+D_{F B_{i}}\right) \cdot Z \cdot L_{V_{i}} \\
& =\sum_{\mathrm{j}=1}^{i} \mathrm{~F}_{\mathrm{j}} \cdot C_{P} \cdot\left(T_{F_{i}}-T_{F_{i+1}}\right)
\end{aligned}
$$

- Rate of heat transfer of $i^{\text {th }}$ feed heater

$$
\begin{aligned}
Q_{F H_{i}} & =\left(\sum_{j=1}^{i} F_{j}\right) \cdot C_{P} \cdot\left(T_{F_{i}}-T_{F_{i+1}}\right) \\
& =U_{F H_{i}} \cdot A_{F H_{i}} \cdot L M T D_{F H_{i}}=D_{F H_{i}} L_{V_{i}}
\end{aligned}
$$


where $U_{F H_{I}}$ is the overall heat transfer coefficient of the $1^{\text {st }}$ feed heater. The logarithmic mean temperature difference of the feed heater can be obtained from:

$$
L M T D_{F H_{i}}=\frac{T_{F_{i}}-T_{F_{i+1}}}{\ln \left(\frac{T_{V_{i}}-T_{F_{i+1}}}{T_{V_{i}}-T_{F_{i}}}\right)}
$$

- Exergy balance of $i^{\text {th }}$ feed heater

$$
\begin{aligned}
X_{F H_{i}}^{\cdot}= & \left(\sum_{\mathrm{j}=1}^{i} \mathrm{~F}_{\mathrm{j}}\right) \cdot\left(C_{P} \Delta T_{F}-T_{O} C_{P} \ln \left(\frac{T_{F_{i+1}}}{T_{F_{i}}}\right)\right) \\
& +Q_{F H_{i}}\left(1-\frac{T_{O}}{T_{V_{i}}}\right)
\end{aligned}
$$

\section{- Steam jet ejector}

The most essential part in modeling the MED-TVC desalination system is to determine the entrainment ratio $\varepsilon$ which is the ratio of the entrained steam to the motive steam $\left(\varepsilon=D_{r} / S\right)$. This ratio depends on the discharge pressure $\mathrm{P}_{\mathrm{d}}$, motive steam pressure $P_{s}$ and entrained vapor pressure $P_{V n}$. In this work, the entrainment ratio $\varepsilon$ is calculated through using the chart developed by Ropert Power [26]. This chart was based on the values of both compression ratio $(C R)$ and expansion ratio $(E R)$. These ratios can be obtained from:

$$
\begin{aligned}
& C R=\left(P_{d} / P_{V_{n}}\right) \\
& E R=\left(P_{s} / P_{V_{n}}\right)
\end{aligned}
$$

\section{- Exergy destruction of steam jet ejector}

The rate of exergy destruction inside ejector can be calculated from the following equation:

$$
\begin{aligned}
X_{\text {ejector }}^{\bullet} & S \cdot\left(h_{s}-h_{d_{1}}-T_{o}\left(s_{s}-s_{d}\right)\right) \\
& +D_{r} \cdot\left(h_{V_{n}}-h_{d}-T_{o}\left(s_{V_{n}}-s_{d}\right)\right)
\end{aligned}
$$

\section{- Energy balance of condenser}

The energy generated during condensation of the amount of vapor entering the condenser $\left(D_{F}\right)$ heats up the seawater from $T_{S W}$ to $T_{F n}$. So,

$$
D_{F} \cdot L_{V_{n}}=M_{S W} \cdot C_{P} \cdot\left(T_{F_{n}}-T_{S W}\right)
$$

\section{- Rate of heat transfer of condenser}

$$
Q_{C}=D_{F} \cdot L_{V_{n}}=U_{C} \cdot A_{C} \cdot L M T D_{C}
$$

where $U_{C}$ is condenser overall heat transfer coefficient. The logarithmic mean temperature difference of condenser can be expressed as:

$$
L M T D_{C}=\frac{T_{S W}-T_{F_{n}}}{\ln \left(\frac{T_{V_{n}}-T_{F_{n}}}{T_{V_{n}}-T_{S W}}\right)}
$$

\section{- Exergy destruction of the condenser}

The exergy destruction of condenser can be expressed as:

$$
\begin{aligned}
X_{C}^{\bullet}= & Q_{C}\left(1-\left(\frac{T_{o}}{T_{V n}}\right)\right) \\
& +M_{S W} \cdot C_{P} \cdot\left(\left(T_{S W}-T_{F_{n}}\right)-T_{o} \ln \left(\frac{T_{S W}}{T_{F_{n}}}\right)\right)
\end{aligned}
$$

Each of $U_{E}, U_{F H}, U_{C}$ can be obtained from correlations from ref.[22].

- Performance parameters.

The most essential performance parameters are:

1- Gain Ratio $(G R)$ which is the ratio of the rate of desalinated water to the rate of motive steam.

$$
G R=D_{t} / S
$$

2- Specific Heat Transfer Area (SHTA) which is the total heat transfer area per $1 \mathrm{~kg} / \mathrm{s}$ of the desalinated water.

$$
S H T A=A_{T} / D_{t}
$$

where $A_{T}$ is the total heat transfer area which is the sum of effects area, feed heaters area and condenser area.

$$
A_{T}=\sum_{i=1}^{n} A_{E_{i}}+\sum_{i=1}^{n} A_{F H_{i}}+A_{C}
$$

3- Specific Total Exergy Destruction (STED) which is the total exergy destruction per $1 \mathrm{~kg} / \mathrm{s}$ of the desalinated water.

$$
\begin{aligned}
& S T E D=X_{T}^{\bullet} / D_{t} \\
& X_{T}^{\bullet}=X_{\text {Ejector }}^{\bullet}+\sum_{i=1}^{n} X_{E_{i}}^{\bullet}+\sum_{i=1}^{n-1} X_{F H_{i}}^{\bullet}+\sum_{i=1}^{n} X_{F B_{i}}^{\bullet}+X_{C}^{\bullet}
\end{aligned}
$$




\section{SOLUTION ALGORITHM}

The model developed in the previous section is highly nonlinear. The model can be solved in the following procedure:

1. Specify the input variables and assign for these variables as shown in table (1).

2. Calculate the total feed water from Eq.(3).

3. Assume constant rate of feed water for each effect and equal temperature difference across effects and feed heaters. Then calculate $T_{2}: T_{n-l}, T_{F_{l}}: T_{F_{n}}$ and $F_{1}: F_{n}$.

4. The entrainment ratio is obtained from a developed subprogram that fits the power's chart[26].

5. Assume initial values $X_{1}: X_{n-1}$

6. Calculate $C_{P}$ and $B P E$ at different temperatures and salt concentrations.

7. Solve the energy balance equations using gauss elimination method to obtain the values of $S$ and $D_{l}: D_{n}$.

8. Calculate the brine rejected from each effect from $X_{I}$ to $X_{n-I}$ using equations (4) and (24).

9. Check if the error in the salt concentration values becomes lower than a specified tolerance otherwise the previous steps from the $6^{\text {th }}$ step are repeated.

10. Calculate the heat transfer area and rate of exergy destruction for the different system components.

11. Calculate GR, SHTA and STED.

\section{MODEL VALIDATION}

The model validation is shown in Table (2) where the present results are compared with the corresponding available data obtained from three commercial plants. These plants are Rabigh, Trapani and another plant. The table shows that the deviation between present model results and actual data falls within the acceptable range and good agreement can be inferred. This means that the present model is reliable and capable of simulating the MED-TVC-PF systems accurately.
Table (1) Initial values of parameters

\begin{tabular}{|c|c|c|}
\hline Input variable & Value & Unit \\
\hline $\mathrm{N}_{\mathrm{E}}$ & 6 & - \\
\hline $\mathrm{D}_{\mathrm{t}}$ & 1 & $\mathrm{~kg} / \mathrm{s}$ \\
\hline $\mathrm{X}_{\mathrm{f}}$ & 36000 & $\mathrm{ppm}$ \\
\hline $\mathrm{X}_{\mathrm{n}}$ & 70000 & $\mathrm{ppm}$ \\
\hline $\mathrm{T}_{\mathrm{sw}}$ & 30 & ${ }^{\circ} \mathrm{C}$ \\
\hline$\Delta \mathrm{T}_{\mathrm{C}}$ & 10 & ${ }^{\circ} \mathrm{C}$ \\
\hline $\mathrm{TBT}$ & 69 & ${ }^{\circ} \mathrm{C}$ \\
\hline $\mathrm{T}_{\mathrm{n}}$ & 43 & ${ }^{\circ} \mathrm{C}$ \\
\hline $\mathrm{P}_{\mathrm{s}}$ & 2500 & $\mathrm{kPa}$ \\
\hline $\mathrm{T}_{\mathrm{d}}$ & 74 & ${ }^{\circ} \mathrm{C}$ \\
\hline
\end{tabular}

Table (2) Model comparison against three plants

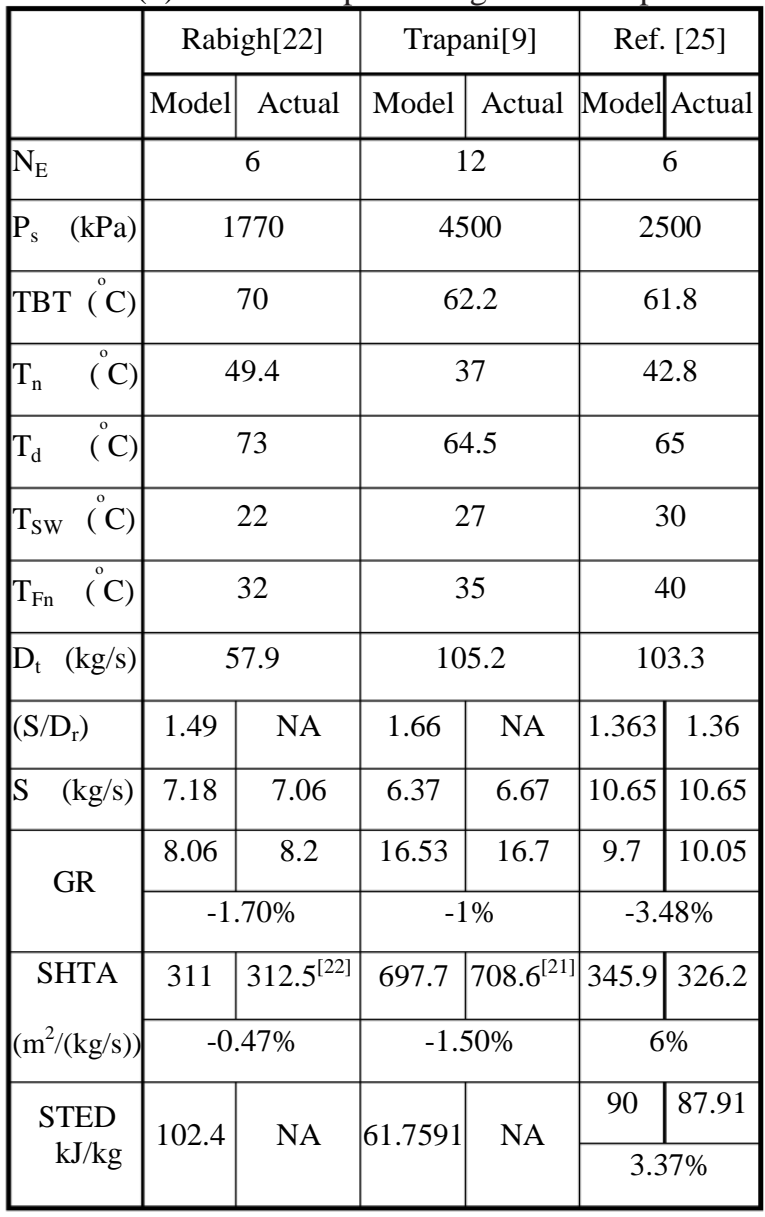




\section{Results and Discussions}

Once the present model proves to be capable to simulate efficiently MED-TVC-PF systems, a series of runs is carried out to study the effect of different design and operating parameters on the performance parameters such as GR, SHTA and STED. The design and operating parameters include: number of effects $\left(\mathrm{N}_{\mathrm{E}}\right)$, temperature of heating steam $\left(\mathrm{T}_{\mathrm{d}}\right)$, temperature of the last effect $\left(\mathrm{T}_{\mathrm{n}}\right)$, salt concentration ratio $\left(\mathrm{X}_{\mathrm{n}} / \mathrm{X}_{\mathrm{f}}\right)$, top brine temperature (TBT), motive steam pressure $\left(\mathrm{P}_{\mathrm{s}}\right)$ and temperature of feed seawater $\left(\mathrm{T}_{\mathrm{sw}}\right)$.

In this study, the effect of parameters will be studied one at a time. During studying the effect of a specified parameter on the system performance, the other parameters are kept at fixed values. These values are listed in Table (1).

\subsection{Effect of $N_{E}$ on performance parameter.}

\subsubsection{Effect of $\mathrm{N}_{\mathrm{E}}$ on GR}

The effect of $N_{E}$ on GR is shown in figure (3). The figure shows that the GR increases with increasing $\mathrm{N}_{\mathrm{E}}$. The main reason of this increase is the increasing of the number of vapor reuse which causes more and more desalinated water. The second reason of increasing GR with $\mathrm{N}_{\mathrm{E}}$ is decreasing the value of the temperature difference across each effect $\left(\Delta T_{E}\right)$.

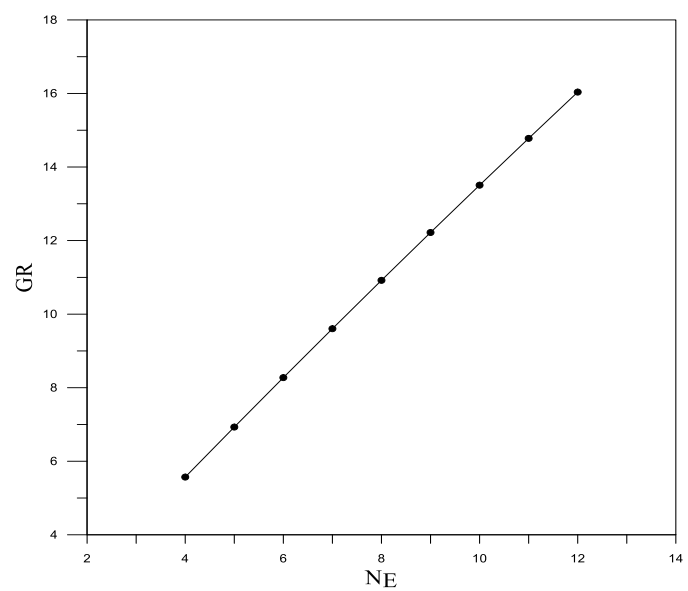

Figure (3) Effect of $\mathrm{N}_{\mathrm{E}}$ on GR

\subsubsection{Effect of $N_{E}$ on SHTA}

Figure (4) shows the effect of $\mathrm{N}_{\mathrm{E}}$ on SHTA. It can be noticed that the SHTA increases with $\mathrm{N}_{\mathrm{E}}$ increasing. This is because increasing $\mathrm{N}_{\mathrm{E}}$ tends to decrease $\Delta \mathrm{T}_{\mathrm{E}}$ which inversely affects the value of SHTA.

It should be mentioned here that increasing SHTA means higher capital cost and consequently distillated product cost. Therefore, the choice of suitable $\mathrm{N}_{\mathrm{E}}$ is very important in the design of the
MED system to keep the balance among the more distillated product, higher capital cost, and heat transfer requirement.

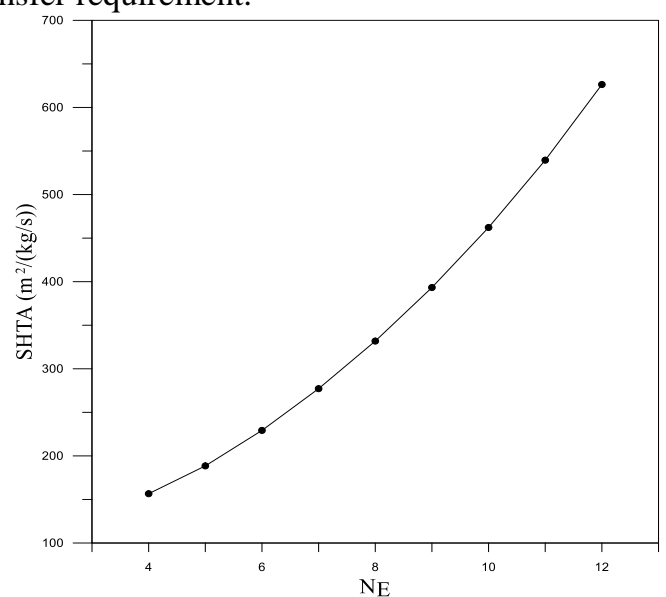

Figure (4) Variation of SHTA with $\mathrm{N}_{\mathrm{E}}$

\subsubsection{Effect of $\mathrm{N}_{\mathrm{E}}$ on STED}

The effect of $\mathrm{N}_{\mathrm{E}}$ on STED is depicted in figure (5). The STED decreases with increasing $\mathrm{N}_{\mathrm{E}}$. This may attributed to increasing $\mathrm{N}_{\mathrm{E}}$ decreases the temperature difference between effects. This tendency causes to decrease the entropy generated inside effects. Therefore, the total exergy destruction decreases.

Figure (6) presents through a pie chart the exergy destroyed within the different parts of the system. It can be seen that the Exergy destruction through ejector is about $60 \%$ of the total Exergy destruction.

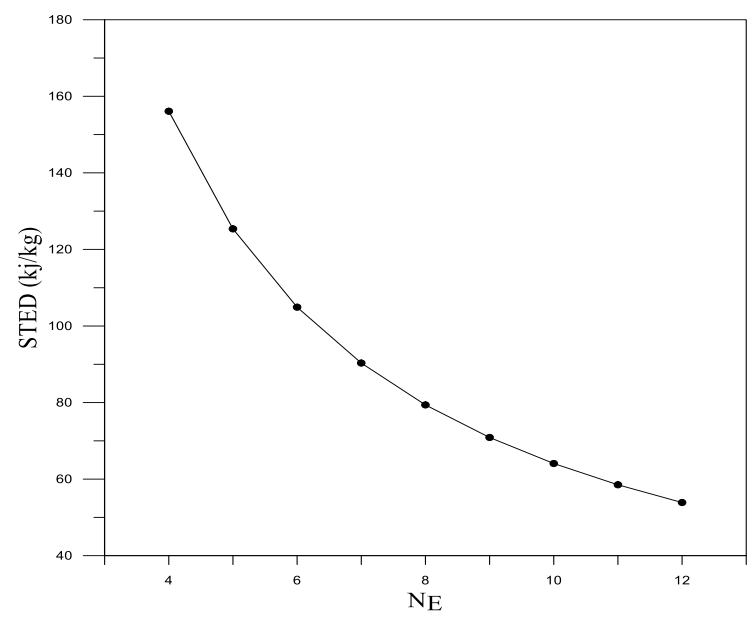

Figure (5) Effect of $\mathrm{N}_{\mathrm{E}}$ on STED 


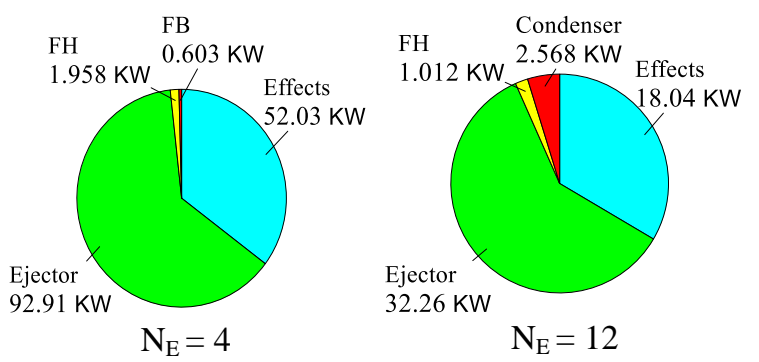

Figure (6) Effect of $\mathrm{N}_{\mathrm{E}}$ on Exergy destruction components

\subsection{Effect of $T_{d}$ on performance parameters}

In this section the effect of temperature of the heating steam $\left(\mathrm{T}_{\mathrm{d}}\right)$ on the performance parameters is studied. $\mathrm{T}_{\mathrm{d}}$ has been changed from $72^{\circ} \mathrm{C}$ to $76^{\circ} \mathrm{C}$ so as not to exceed the Power's chart limit of CR.

\subsubsection{Effect of $T_{d}$ on GR}

The effect of $T_{d}$ on GR is shown in figure (7). The figure shows that the GR slightly decreases with $T_{d}$. This is because of the decrease in the latent heat of condensation with increasing the heating steam temperature, so the system needs more of the heating steam, consequently GR decreases. Another reason of the slight decrease in GR or the slight increase in the motive steam is the decrease in the entrained vapor $D_{r}$. This is because of increasing the ejector compression ratio which accompanied by increasing both the pressure and temperature of heating steam.

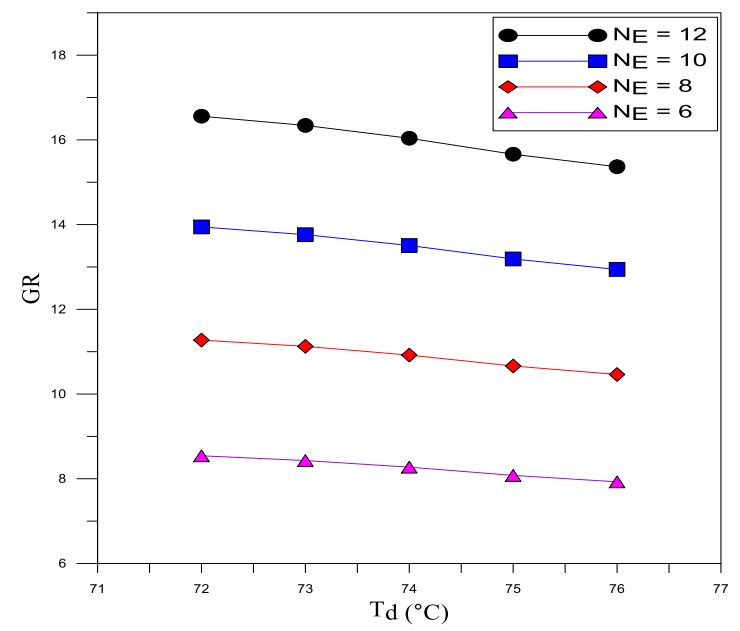

Figure (7) Effect of $\mathrm{T}_{\mathrm{d}}$ on GR

\subsubsection{Effect of $T_{d}$ on SHTA}

Effect of $T_{d}$ on SHTA is shown in figure (8). The figure indicates that SHTA decreases slightly as $T_{d}$ increases. This is because increasing $T_{d}$ increases the difference between TBT and $\mathrm{T}_{\mathrm{d}}$. So, the area of first effect decreases which consequently decreases the
SHTA. The figure also shows that increasing $T_{d}$ from $72{ }^{\circ} \mathrm{C}$ to $76{ }^{\circ} \mathrm{C}$ causes a decrease in SHTA by about $12 \%$.

It is recommended that the temperature difference between $\mathrm{T}_{\mathrm{d}}$ and TBT to be equal to $\Delta \mathrm{T}_{\mathrm{E}}$. Therefore, the areas of all effects are equal, which is a practical demand.

\subsubsection{Effect of $T_{d}$ on STED}

The effect of $T_{d}$ on STED is presented in figures (9), (10) and (11). Figure (9) shows that STED increases with $T_{d}$. This is because increasing $T_{d}$ increases the difference between TBT and $T_{d}$ so the exergy destruction in the first effect and ejector increases as shown in figure (10).

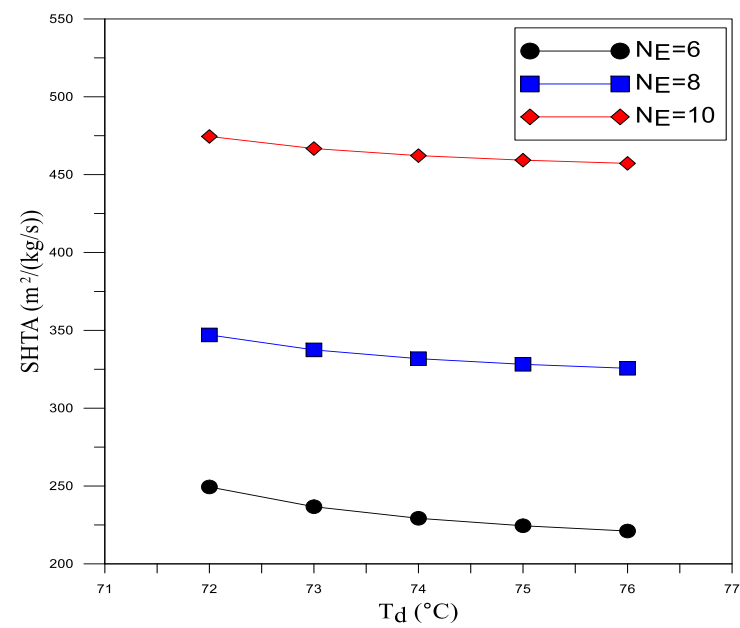

Figure (8) Effect of $\mathrm{T}_{\mathrm{d}}$ on SHTA

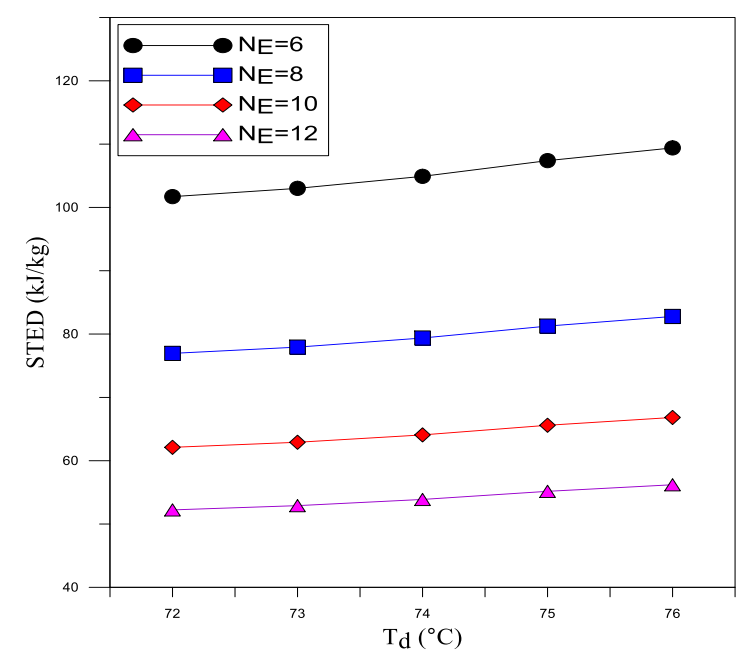

Figure (9) Effect of $T_{d}$ on STED 


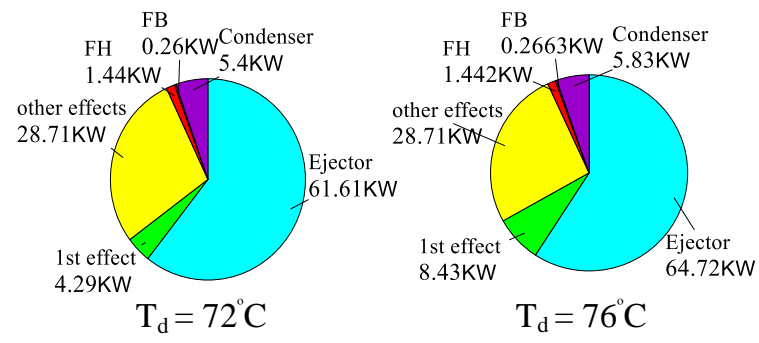

Figure (10) Effect of $T_{d}$ on Exergy destruction components

\subsection{Effect of $T_{n}$ on performance parameters.}

In this section the effect of temperature of the last effect $\left(T_{n}\right)$ on the performance parameters is studied. $\mathrm{T}_{\mathrm{n}}$ is changed while the seawater temperature is kept constant.

\subsubsection{Effect of $T_{n}$ on GR.}

Effect of $T_{n}$ on GR is presented in figure (11). It can be seen that increasing $T_{n}$ causes a decrease in $\Delta T_{E}$ which decreases the generated vapor by flashing inside both flashing boxes and effects. So, the required steam for heating the first effect $\left(S+D_{r}\right)$ increases.

It is obvious that the increase in $T_{n}$ at constant $T_{S W}$ increases the difference between the temperature of feed water to effects and the boiling temperature inside effects. So, the required sensible heat to reach the boiling temperature increases. Also, this increases the required heating steam for the first effect.

On the other hand, increasing $\mathrm{T}_{\mathrm{n}}$ causes to increase the suction pressure of ejector. Therefore, both compression and expansion ratios of the ejector decrease so the entrainment ratio increases and consequently the entrained vapor $\left(D_{r}\right)$ increases. If the rate of $D_{r}$ increase is more than the rate of increase in $\left(S+D_{r}\right)$, the motive steam rate $(S)$ decreases and GR increases and vice versa. This interprets why for ten number of effects, the gain ratio decreases and then increases.

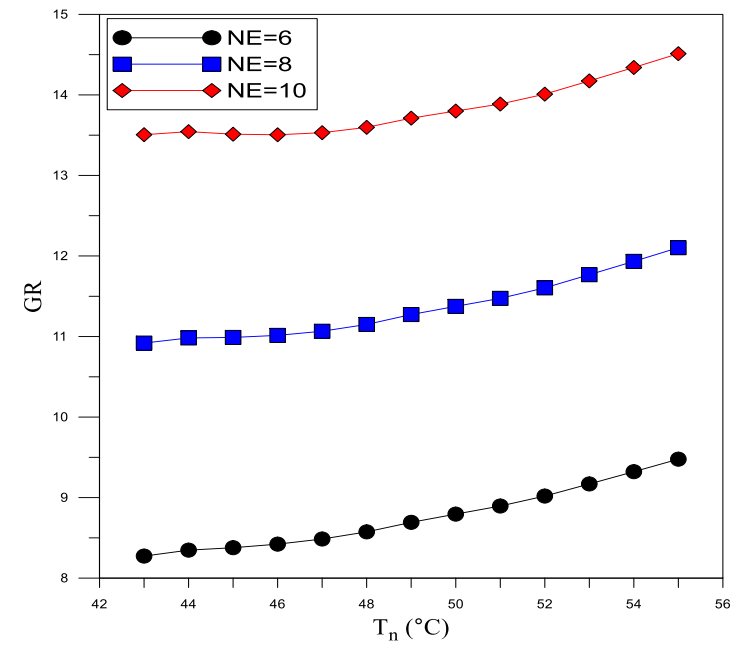

Figure (11) Effect of $T_{n}$ on GR

\subsubsection{Effect of $T_{n}$ on SHTA}

Effect of $T_{n}$ on SHTA has been released in figure (12). The figure shows that SHTA increases with $T_{n}$ increasing. This is because increasing $T_{n}$ decreases both $\Delta \mathrm{T}_{\mathrm{E}}$ and $\Delta \mathrm{T}_{\mathrm{F}}$. Therefore the required area of heat transfer of effects and feed heaters increases. So, SHTA increases.

\subsubsection{Effect of $T_{n}$ on STED}

Effect of $T_{n}$ on STED is shown in figures (13) and (14). These figures show that increasing $T_{n}$ decreases the STED. This is because the motive steam (S) decreases with $T_{n}$. Therefore the exergy input decreases with $\mathrm{T}_{\mathrm{n}}$.

Increasing $T_{n}$ leads to increase the temperature of both total brine and desalinated water rejected from the system and consequently the exergy of the output streams. The rate of decrease in exergy input is higher than the rate of increase in exergy output. So, the STED decreases with $T_{n}$.

Figure (14) shows that increasing $T_{n}$ causes the exergy destruction to increase in condenser and to decrease in ejector. 


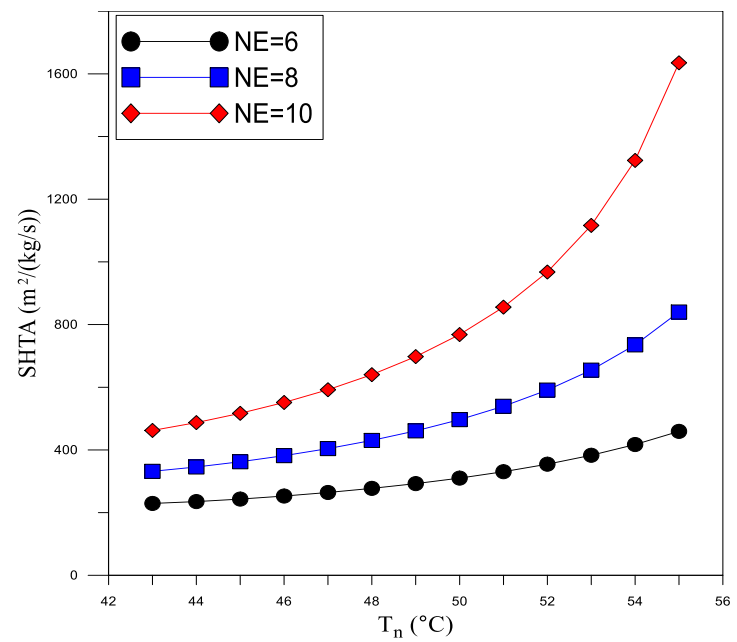

Figure (12) Effect of $T_{n}$ on SHTA

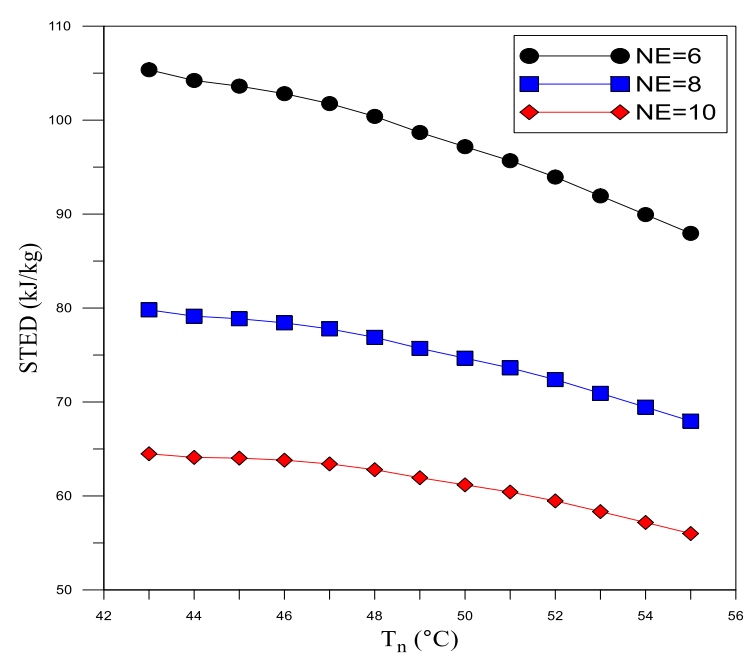

Figure (13) Effect of $T_{n}$ on STED
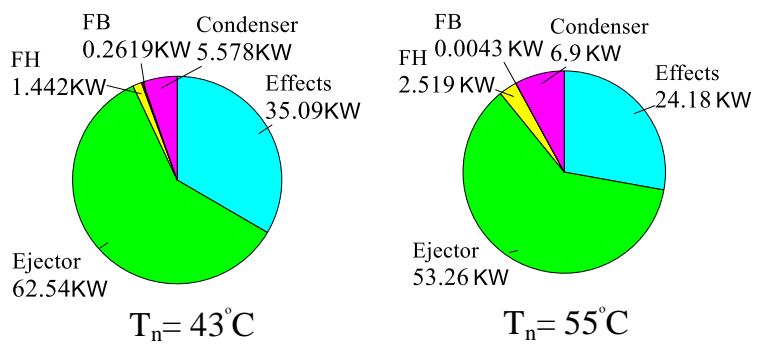

Figure (14) Effect of $T_{n}$ on Exergy destruction components for $\mathrm{N}_{\mathrm{E}}=6$

6.4 Effect of salt concentration ratio $\left(\mathrm{X}_{\mathrm{n}} / \mathrm{X}_{\mathrm{f}}\right)$ on performance parameters

In this section the effect of the ratio of salt concentration of rejected brine to the salt concentration of the feed seawater on the performance parameters is studied. This ratio is changed from 1.2 to 4.2 at a constant concentration of feed water at 36000 PPM.

\subsubsection{Effect of $\left(X_{n} / X_{f}\right)$ on GR}

The effect of $\left(X_{n} / X_{f}\right)$ on GR is shown in figure (15).The figure shows that the value of GR increases at lower concentration ratios then decreases slightly at higher ratios. This is because at lower concentration ratios, the feed flow rate decreases rapidly and then decreases slightly in the higher ratios as it can be noticed from equation (3).

Decreasing the feed flow rate causes decreasing the flow rate of the heating steam of the first effect. This is because of decreasing the required sensible heat to raise the temperature of feed water to the boiling temperature so, the GR increases.

On the other hand, increasing concentration ratio means increasing the value of $X_{n}$, so the BPE for the last effect, which depends on $X_{n}$, increases. Therefore, $T_{\mathrm{Vn}}$ and consequently $\mathrm{P}_{\mathrm{n}}$ decrease, causing the ejector both compression and expansion ratio to increase. So the entrainment ratio decreases causing the entrained vapor $D_{r}$ to decrease, and motive steam $\mathrm{S}$ to increase. Therefore GR decreases.

If the effect of decreasing the feed flow rate on the GR is more than the effect of decreasing $P_{n}$, the GR increases and vice versa.

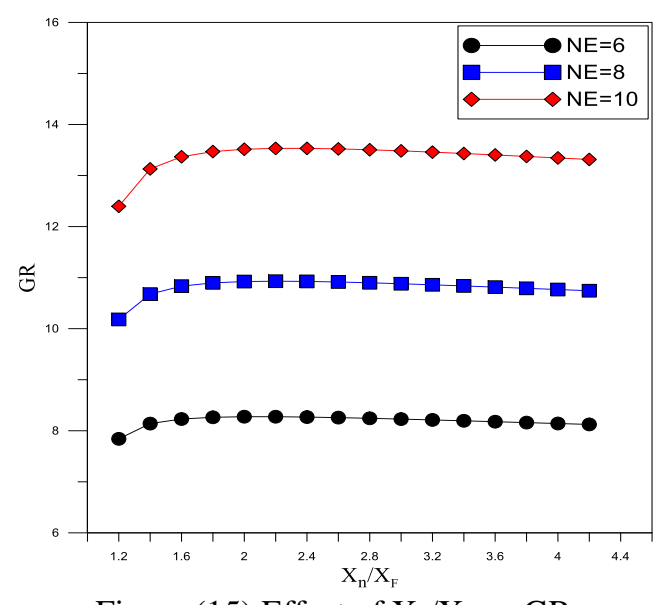

Figure (15) Effect of $X_{n} / X_{f}$ on GR

\subsubsection{Effect of $\left(X_{n} / X_{f}\right)$ on SHTA}

The effect of $\left(\mathrm{X}_{\mathrm{n}} / \mathrm{X}_{\mathrm{f}}\right)$ on SHTA is shown in figure (16). The figure shows that the SHTA increases with $\left(X_{n} / X_{f}\right)$. This is because increasing $X_{n}$ decreases the total feed flow rate which decreases the sensible heat required for feed heaters. So, the remained vapor to condense inside effect increases. Therefore the area of heat transfer of effects increases. 


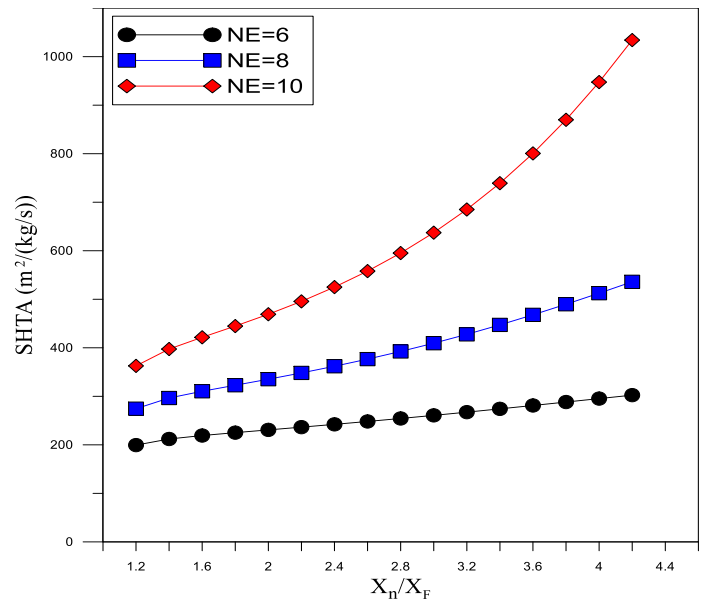

Figure (16) Effect of $\mathrm{X}_{\mathrm{n}} / \mathrm{X}_{\mathrm{f}}$ on SHTA

\subsubsection{Effect of $\left(X_{n} / X_{f}\right)$ on STED}

It can be seen from figure (17) that at lower concentration ratios the STED decreases then increases at higher ones. This is due to decreasing the exergy input in the lower values of $\left(\mathrm{X}_{\mathrm{n}} / \mathrm{X}_{\mathrm{f}}\right)$ and increasing it for higher ones at a constant value of exergy output.

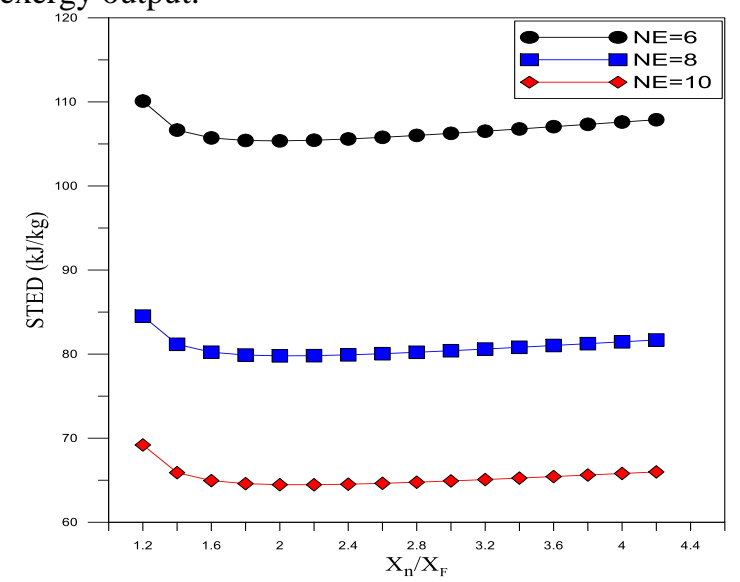

Figure (17) Effect of $X_{n} / X_{f}$ on STED

It can be seen from figures $(15,17)$ that the maximum GR and minimum STED can be achieved be setting the salt concentration ratio in the range of 1.8 to 2.2 .

\subsection{Effect of Top Brine Temperature (TBT) on performance parameters}

In this section the effect of the TBT on the performance parameters is studied. The TBT has been changed from $55^{\circ} \mathrm{C}$ to $71^{\circ} \mathrm{C}$ at a constant temperature of the first effect heating at $74^{\circ} \mathrm{C}$.

\subsubsection{Effect of TBT on GR}

The effect of TBT on the GR is given in Figure (18). It can be noticed that the GR slightly decreases with TBT. This is because increasing TBT increases both $\Delta \mathrm{T}_{\mathrm{E}}$ and $\Delta \mathrm{T}_{\mathrm{F}}$.

Increasing $\Delta \mathrm{T}_{\mathrm{E}}$ increases the generated vapor by flashing inside both flashing boxes and effects so, the required steam as a heat source to the first effect decreases. On the other hand, increasing $\Delta \mathrm{T}_{\mathrm{F}}$ increases the sensible heat used for feed water heating inside feed heaters this increases the required heating steam for the first effect.

The rate of increasing of the first effect heating steam due to increasing $\Delta \mathrm{T}_{\mathrm{F}}$ is more than the rate of decreasing due to increasing $\Delta \mathrm{T}_{\mathrm{E}}$. Therefore the rate of motive steam slightly increases and the GR slightly decreases.

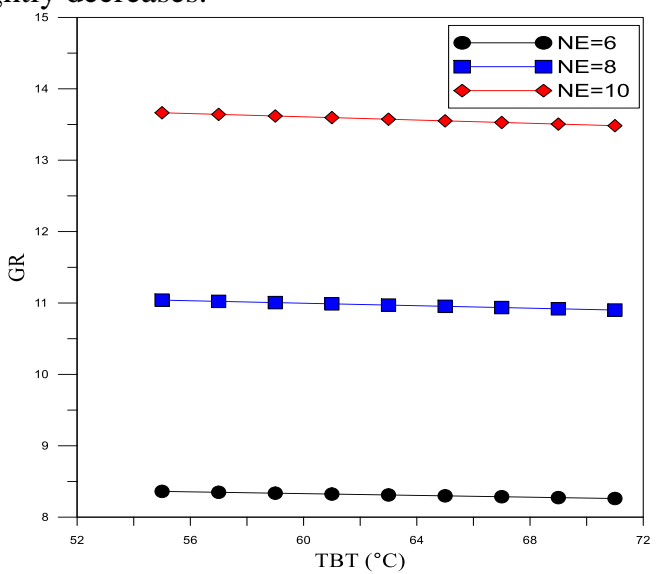

Figure (18) Effect of TBT on GR

\subsubsection{Effect of TBT on SHTA}

The effect of TBT on SHTA is shown in figure (19). It can be noticed that SHTA decreases with TBT. This is because increasing TBT increases the temperature difference across each effect $\Delta \mathrm{T}_{\mathrm{E}}$ which consequently decreases the heat transfer area of each effect. Therefore the SHTA decreases.

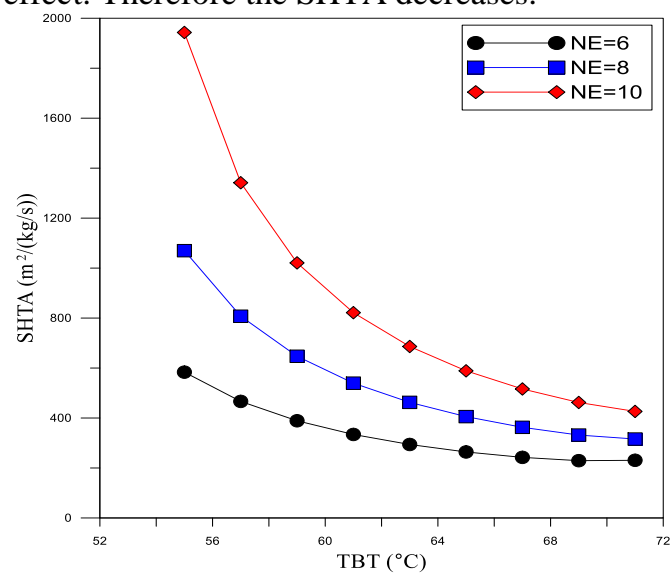

Figure (19) Effect of TBT on SHTA 


\subsubsection{Effect of TBT on STED}

The effect of TBT on STED is shown in figure (20).It is noticed that the STED increases slightly with TBT. This is because of the slight increase the exergy input to the system due to the slight increase in the motive steam.

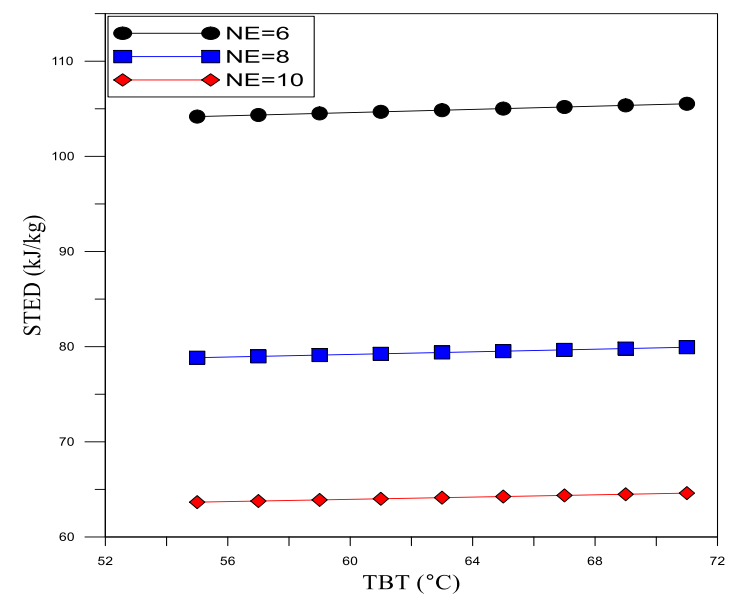

Figure (20) Effect of TBT on STED

6.6 Effect of motive steam pressure $\left(P_{s}\right)$ on performance parameters.

In this section the effect of the pressure of the motive steam entering the ejector on the performance parameters is studied. The $\mathrm{P}_{\mathrm{s}}$ has been changed from 400 to $4900 \mathrm{kPa}$.

\subsubsection{Effect of $P_{s}$ on GR}

The effect of Ps on STED is shown in figure (20). It is seen that the GR increases with $\mathrm{P}_{\mathrm{s}}$. This is because Increasing $\mathrm{P}_{\mathrm{s}}$, increases expansion ratio of ejector while it's compression ratio remains constant, so the entrainment ratio and consequently entrained vapor increase. Therefore the motive steam decreases, so the performance ratio increases.

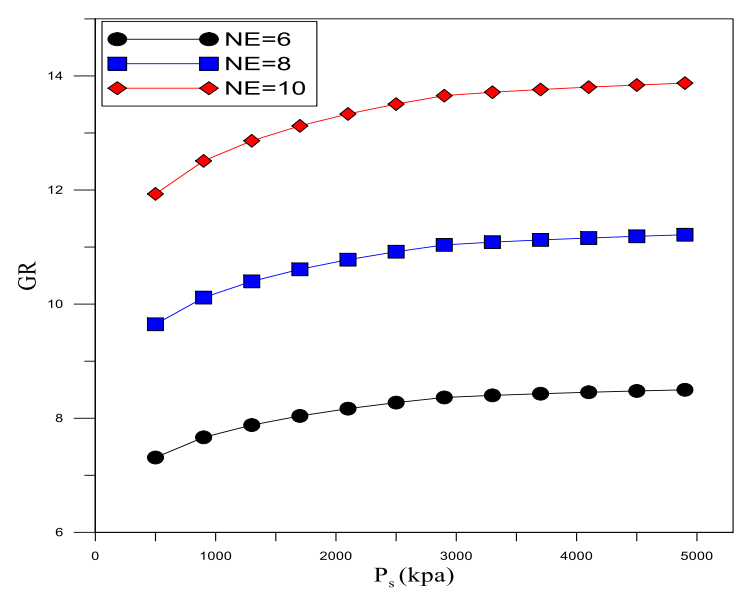

Figure (20) Effect of $\mathrm{P}_{\mathrm{s}}$ on GR

\subsubsection{Effect of $P_{s}$ on SHTA}

The effect of $\mathrm{P}_{\mathrm{s}}$ on SHTA is depicted in figure (21). The figure shows that the SHTA decreases slightly with $P_{s}$. This is because Increasing $P_{s}$ causes increasing $D_{r}$ which decreases the amount of vapor entering the condenser as a heat source; this decreases the amount of heat transfer and accordingly the area of condenser, which is a part of the total heat transfer area.

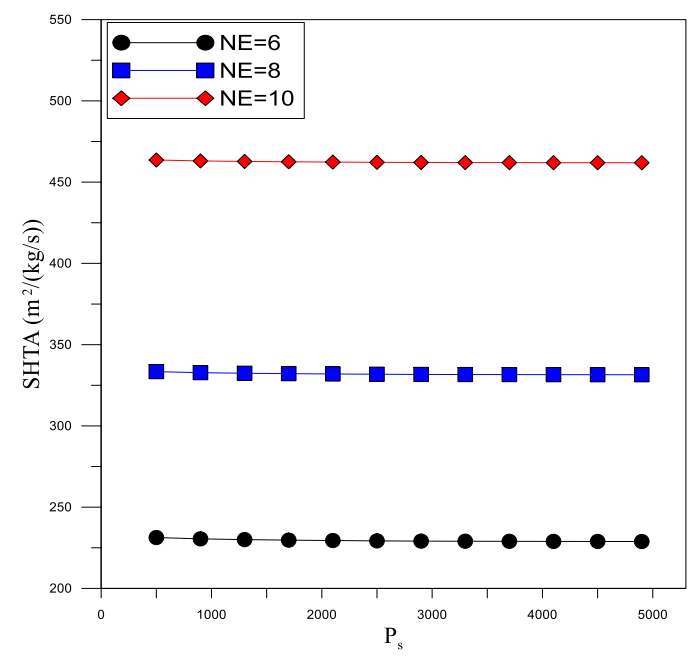

Figure (21) Effect of $\mathrm{P}_{\mathrm{s}}$ on SHTA

\subsubsection{Effect of $P_{s}$ on STED}

The effect of $\mathrm{P}_{\mathrm{s}}$ on STED is shown in figure (22). It is clear from these figures that the STED increases with $\mathrm{P}_{\mathrm{s}}$. This is because increasing in $\mathrm{P}_{\mathrm{s}}$ means increasing in $T_{S}$ which is the saturation temperature at $P_{s}$. Increasing $T_{s}$ at constant temperatures at the suction and discharge of ejector causes increasing in the entropy generation and exergy destruction inside ejector.

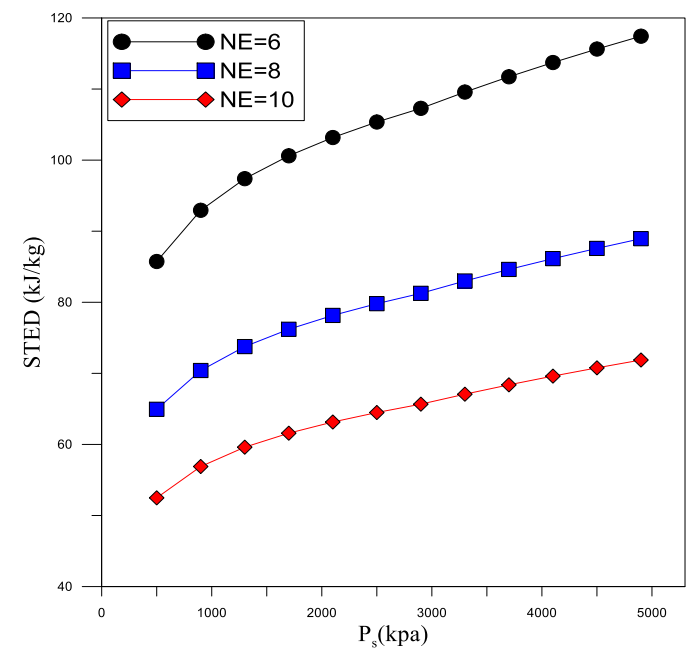

Figure (22) Effect of $\mathrm{P}_{\mathrm{s}}$ on STED 


\section{CONCLUSIONS}

In this paper a mathematical model for the parallel feed MED-TVC system is developed. The model is based on the first and second laws of thermodynamics. A MATLAB code is developed for the solution of the model. The comparison between the developed program results and data obtained for actual plants shows a good agreement which indicates the model accuracy. The effects of different design and operation parameters of parallel feed MED-TVC system on its performance parameters are investigated. From this parametric study it can be concluded that:

1- As $\mathrm{N}_{\mathrm{E}}$ and $\mathrm{T}_{\mathrm{n}}$ increase, both GR and STED decreases while SHTA increases. Therefore the values of $\mathrm{N}_{\mathrm{E}}$ and $\mathrm{T}_{\mathrm{n}}$ must be optimized costly.

2- Although the heating steam temperature has a slight effect on the performance parameters. So, it is recommended that the temperature between $\mathrm{T}_{\mathrm{d}}$ and TBT to be equal to $\Delta \mathrm{T}_{\mathrm{E}}$.

3- GR increases with increasing each of $\mathrm{N}_{\mathrm{E}}$, temperature of last effect, salt concentration up to 2 and motive steam pressure. While GR decreases with increasing TBT and $\mathrm{T}_{\mathrm{d}}$.

4- To achieve the maximum GR and minimum STED, the salt concentration ratio must be in the range of 1.8 to 2.2 .

5- Increasing the value of TBT affects GR and STED very slightly but it drastically decreases the SHTA. A value lower than $\mathrm{T}_{\mathrm{d}}$ by $\Delta \mathrm{T}_{\mathrm{E}}$ is recommended for TBT.

6- Increasing the motive steam pressure increases GR and decreases SHTA but it greatly increases the STED.

\section{Nomenclature}

$\mathrm{A}_{\mathrm{C}} \quad$ Heat transfer area of the condenser, $\mathrm{m}^{2}$

$\mathrm{A}_{\mathrm{FHi}} \quad$ Heat transfer Area of $\mathrm{i}^{\text {th }}$ feed heater, $\mathrm{m}^{2}$

$\mathrm{A}_{\mathrm{i}} \quad$ Heat transfer Area of $\mathrm{i}^{\mathrm{t}}$ effect, $\mathrm{m}^{2}$

$\mathrm{A}_{\mathrm{T}} \quad$ Total heat transfer area, $\mathrm{m}^{2}$

$\mathrm{B}_{\mathrm{i}} \quad$ Flow rate of brine leaving the $\mathrm{i}^{\text {th }}$ effect, $\mathrm{kg} / \mathrm{s}$

$\mathrm{B}_{\mathrm{n}} \quad$ Total rate of brine leaving the system, $\mathrm{Kg} / \mathrm{s}$

CR Ejector's Compression Ratio

ER Ejector Expansion Ratio

$\mathrm{C}_{\mathrm{p}} \quad$ Specific heat capacity, kJ/kg.K

$D_{i} \quad$ Generated Vapor of $i^{\text {th }}$ effect, $\mathrm{kg} / \mathrm{s}$

$\mathrm{D}_{\mathrm{F}} \quad$ Vapor condensed in condenser, $\mathrm{kg} / \mathrm{s}$

$\mathrm{D}_{\mathrm{FBi}} \quad$ Generated Vapor of $\mathrm{i}^{\text {th }}$ flashing box, $\mathrm{kg} / \mathrm{s}$

$\mathrm{D}_{\mathrm{r}} \quad$ Entrained Vapor flow rate, $\mathrm{kg} / \mathrm{s}$

$\mathrm{D}_{\mathrm{t}} \quad$ Total desalinated water, $\mathrm{kg} / \mathrm{s}$

$\mathrm{F}_{\mathrm{i}} \quad$ Feed water to $\mathrm{i}^{\text {th }}$ effect, $\mathrm{kg} / \mathrm{s}$

$\mathrm{F}_{\mathrm{t}} \quad$ Total feed water rate, $\mathrm{kg} / \mathrm{s}$

$\mathrm{L}_{\mathrm{d}} \quad$ Latent heat of heating steam, $\mathrm{kJ} / \mathrm{kg}$

$\mathrm{L}_{\mathrm{Vi}} \quad$ Latent heat of vapor generated from the $i^{\text {th }}$ effect, $\mathrm{kJ} / \mathrm{kg}$
$\mathrm{M}_{\mathrm{CW}} \quad$ Cooling water flow rate, $\mathrm{kg} / \mathrm{s}$

$\mathrm{M}_{\mathrm{SW}} \quad$ Seawater mass flow rate, $\mathrm{kg} / \mathrm{s}$

$\mathrm{N}_{\mathrm{E}} \quad$ Number of Effects

$\mathrm{m}^{\mathrm{o}} \quad$ Mass flow rate, $\mathrm{kg} / \mathrm{s}$

$\mathrm{P}_{\mathrm{s}} \quad$ Motive steam pressure, $\mathrm{kPa}$

$\mathrm{P}_{\mathrm{Vi}} \quad$ Pressure of vapor leaving $\mathrm{i}^{\text {th }}$ effect, $\mathrm{kPa}$

$\mathrm{P}_{\mathrm{Vn}} \quad$ Pressure of entrained vapor, $\mathrm{kPa}$

$\mathrm{Q}_{\mathrm{C}} \quad$ Rate of heat transfer of condenser, $\mathrm{kW}$

$\mathrm{Q}_{\mathrm{Ei}} \quad$ Rate of heat transfer of $\mathrm{i}^{\text {th }}$ effect, $\mathrm{kW}$

$\mathrm{Q}_{\mathrm{FHi}} \quad$ Rate of heat transfer of $\mathrm{i}^{\text {th }}$ feed heater, $\mathrm{kW}$

$\mathrm{S} \quad$ Motive steam flow rate, $\mathrm{kg} / \mathrm{s}$

$\mathrm{T}_{\mathrm{d}} \quad$ Heating steam temperature, ${ }^{\circ} \mathrm{C}$

$\mathrm{T}_{\mathrm{Fi}} \quad$ Temperature of feed water to $\mathrm{i}^{\text {th }}$ effect, ${ }^{\circ} \mathrm{C}$

$\mathrm{T}_{\mathrm{i}} \quad$ Boiling Temperature of $\mathrm{i}^{\text {th }}$ effect, ${ }^{\circ} \mathrm{C}$

$\mathrm{T}_{\mathrm{SW}} \quad$ Seawater Temperature, ${ }^{\circ} \mathrm{C}$

$\mathrm{T}_{\mathrm{Vi}} \quad$ Temperature of vapor generated from $i^{\text {th }}$ effect, ${ }^{\circ} \mathrm{C}$

TBT Top Brine Temperature, ${ }^{\circ} \mathrm{C}$

$\mathrm{T}_{\mathrm{Fn}} \quad$ Feed water temperature after condenser, ${ }^{\circ} \mathrm{C}$

$\mathrm{U}_{\mathrm{Ci}}$ Overall heat transfer coefficient of $\mathrm{i}^{\text {th }}$ effect, $\mathrm{kW} / \mathrm{m}^{2} .{ }^{\circ} \mathrm{C}$

$\mathrm{U}_{\mathrm{Ei}} \quad$ Overall heat transfer coefficient of $\mathrm{i}^{\text {th }}$ effect, $\mathrm{kW} / \mathrm{m}^{2} .{ }^{\circ} \mathrm{C}$

$\mathrm{U}_{\mathrm{FHi}} \quad$ Overall heat transfer coefficient of $i^{\text {th }}$ feed heater, $\mathrm{kW} / \mathrm{m}^{2} .{ }^{\circ} \mathrm{C}$

$X_{E_{i}} \quad$ Exergy destruction of $\mathrm{i}^{\text {th }}$ effect, $\mathrm{kW}$

$X_{E j e c t o r}^{*}$ Exergy destruction of ejector, $\mathrm{kW}$

$X_{F H_{i}}^{*} \quad$ Exergy destruction of $i^{\text {th }}$ feed heater, $\mathrm{kW}$

$X_{F B_{i}} \quad$ Exergy destruction of $\mathrm{i}^{\text {th }}$ flashing box, $\mathrm{kW}$

$X_{i} \quad$ Salt concentration of brine leaving the $i^{\text {th }}$ effect, ppm

$X_{n} \quad$ Salt concentration of brine leaving the last effect, ppm

$X_{T}^{*} \quad$ Total Exergy destruction, $\mathrm{kW}$

\section{Greek symbols}

$\psi \quad$ Specific exergy, $\mathrm{kJ} / \mathrm{kg}$.

$\Delta \mathrm{T}_{\mathrm{C}} \quad$ Condenser temperature difference, ${ }^{\circ} \mathrm{C}$

$\Delta \mathrm{T}_{\mathrm{E}} \quad$ Effect temperature difference, ${ }^{\circ} \mathrm{C}$

$\Delta \mathrm{T}_{\mathrm{F}} \quad$ Feed heater temperature difference, ${ }^{\circ} \mathrm{C}$

\section{Abbreviations}

BPE Boiling Point Elevation, ${ }^{\circ} \mathrm{C}$

FB Flashing Box

FH Feed Heater

GR Gain Ratio

LMTD Logarithmic Mean Temperature Difference, ${ }^{\circ} \mathrm{C}$

MED Multi Effect Desalination

MSF Multi Stage Flash desalination

MVC Mechanical Vapor Compression

RO Reverse Osmosis

SHTA Specific Heat Transfer Area, $\mathrm{m}^{2} /(\mathrm{kg} / \mathrm{s})$

STED Specific Total Exergy Destruction, $\mathrm{kJ} / \mathrm{kg}$

TVC Thermal Vapor Compression 


\section{REFERENCES}

[1] United Nations "Water for people Water for life", The UN World Water Development Report, UNESCO Publishing, 2003.

[2] M.A. Darwish "Technical aspects of reducing desalting water costs in distillation methods", Desalination, Vol. 72, pp.381-393, 1989.

[3] M.A. Darwish, Faisal Al-Juwayhel and H. Abdulraheim, "Multi-effect boiling systems from an energy viewpoint", Desalination, Vol. 194, pp.22-39, 2006.

[4] M. Al-Shammiri and M. Safar, "Multi-effect distillation plant: state of the art", Desalination, Vol. 126, pp.45-59, 1999.

[5] H.T. El-Dessouky and H.M. Ettouney, "Multiple effect evaporation desalination systems: thermal analysis", Desalination, Vol. 125, pp.259-276, 1999.

[6] M. Abdel-Jawad, "Energy options for water desalination in selected ESCWA member countries", UN, New York, 2001.

[7]Hisham T. El Dessouky and Ghazy M.R. Assassa, "Computer simulation of the horizontal falling film desalination plants", Desalination, Vol. 55, pp.119$138,1985$.

[8] M. Darwish and H. El-Dessouky, "The heat recovery thermal vapour-compression desalting system: a comparison with other thermal desalination processes", Appl. Therm. Eng., Vol. 16, pp. 523$537,1996$.

[9] C. Temstet, G. Canton, J. Laborie and A. Duranti, "A large high-performance MED plant in Sicily", Desalination, Vol. 105, pp. 109-114, 1996.

[10] H.M. Ettouney, H. El-Dessouky, "A simulator for thermal desalination processes", Desalination, Vol. 125, pp. 277-291, 1999.

[11] Hisham T. El-Dessouky, Hisham M. Ettouney, Faisal Mandani, "Performance of parallel feed multiple effect evaporation system for seawater desalination", Applied Thermal Engineering, Vol. 20, pp. 1679-1706, 2000.

[12] A. Jernqvist, M. Jernqvist. G. Aly, "Simulation of thermal desalination processes", Desalination, Vol. 134, pp. 187-193, 2001.

[13] M.M. Ashour, "Steady state analysis of the Tripoli West LT-HT-MED plant”, Desalination, Vol. 152, pp. 191-194, 2003.

[14] H.S. Aybar, "Desalination system using waste heat of power plant", Desalination, Vol. 166, pp. 167-170, 2004.

[15] Hisham Ettouney, "Visual basic computer package for thermal and membrane desalination processes", Desalination, Vol. 165, pp. 393-408, 2004.

[16]A.S. Nafey, H.E.S. Fath, A.A. Mabrouk, “A new visual package for design and simulation of desalination processes", Desalination, Vol. 194, pp. 281-296, 2006.
[17] M. Ameri, M. Hosseini, S. Seif Mohammadi and M.R. Shamshirgaran, "Steady-state mathematical modeling of multi-effect desalination to produce potable water using gas turbine flue gas", Proc. Inter. Conference on Modeling and Simulation, Kuala Lumpur, Malaysia, pp. 66, 2006.

[18] J. Ji, R. Wang, L. Li, H. Ni, "Simulation and analysis of a single effect thermal vapor compression desalination system at variable operation conditions", Chem. Eng. Technol., vol. 30, pp. 1633-1641, 2007. [19] R.K. Kamali, S. Mohebinia, "Experience of design and optimization of multi-effects desalination systems in Iran", Vol. 222, pp. 639-645, 2008.

[20] Mohammad Ameri, Saeed Seif Mohammadi, Mehdi Hosseini, Maryam Seifi, "Effect of design parameters on multi-effect desalination system specifications", Desalination, Vol. 245, pp. 266-283, 2009.

[21] A.O. Bin Amer, "Development and optimization of ME-TVC desalination system”, Desalination, Vol. 249, pp. 1315-1331, 2009.

[22] I.S. Al-Mutaz, Irfan Wazeer, "Development of a steady-state mathematical model for MEE-TVC desalination plants", Desalination, Vol. 351, pp.918, 2014.

[23] O. A. Hamed, 1 A. M. Zamamiri, S. Aly and N. Lior, "Thermal performance and exergy analysis of a thermal vapor compression desalination system", EnergyConvers.Mgmt, Vol. 37, pp. 379-387, 1996

[24] Chennan Li, D. Yogi Goswami , Andrew Shapiro, Elias K. Stefanakos , Gokmen Demirkaya, "A new combined power and desalination system driven by low grade heat for concentrated brine", Energy, Vol. 46, pp. 582-595, 2012.

[25] F.N. Alasfour, M.A. Darwish, A.O. Bin Amer, "Thermal analysis of ME-TVC+MEE desalination systems", Desalination, Vol. 174, pp. 39-61, 2005.

[26] R.B. Power, "Steam Jet Ejectors for the Process Industries", McGraw-Hill, 1994. 